\title{
Nurses' attitudes towards Do Not Attempt Resuscitation orders
}

\author{
Shane O'Hanlon ${ }^{1}$, Marie O'Connor ${ }^{2}$, Catherine Peters ${ }^{3}$, Mike O'Connor ${ }^{2}$ \\ 1. Graduate Entry Medical School, University of Limerick, Ireland. 2. Department of Geriatric Medicine, Cork University \\ Hospital, Wilton, Cork, Ireland. 3. Division of Geriatric Medicine, University Hospital, Limerick, I reland.
}

Correspondence: Shane O'Hanlon. Address: Graduate Entry Medical School, University of Limerick, Castletroy, Limerick, Ireland. Email: shane.ohanlon@ul.ie

Received: November 26, 2012

Accepted: February 3, 2013

Online Published: February 26, 2013

DOI : $10.5430 /$ cns.v1n1p43

URL: http://dx.doi.org/10.5430/cns.v1n1p43

\section{Abstract}

Introduction: Do Not Attempt Resuscitation (DNAR) orders represent a difficult and challenging area of practice for many health professionals. Many studies have examined the perspective of physicians, but recent changes have enhanced the role of nurses in the UK. Despite this, there remains a knowledge gap regarding their interactions with DNAR orders.

Aim: To explore the opinions and experiences of nursing staff on DNAR orders.

Methods: We surveyed nursing staff in a major teaching hospital using a structured tool.

Results: 251 nurses were invited to participate in the study. 178 completed forms were received (response rate 70.9\%). One third of respondents reported the presence of a resuscitation policy on their ward, although no official policy existed in the hospital. 91\% of nurses would resuscitate by default if no decision on DNAR had been made. Most believed that consultants or patients should make decisions, and felt it was the role of the physician to inform the patient. $70 \%$ stated that DNAR orders were only clear "sometimes"; and 15\% that physicians never discuss them with nurses. 52\% said that all hospital patients should be routinely asked if they would like to be resuscitated. $35 \%$ have disagreed with a DNAR decision. Nurses overestimated the mean survival rate at cardiac arrests to be $34 \% .76 \%$ believe they need more training.

Conclusion: There is considerable interest in DNAR orders among nursing staff. There was dissatisfaction with regard to how DNAR orders work, including a perceived lack of communication from physicians and lack of clarity in the orders. There is a need for further education and cooperation in this area.

\section{Key words}

Do Not Attempt Resuscitation orders, Resuscitation, Nurses, Attitudes, Survey

\section{I ntroduction}

Do Not Attempt Resuscitation (DNAR) orders represent a difficult and challenging area for many healthcare practitioners. Cardiopulmonary resuscitation (CPR) came into practice in the 1960s to try to restore circulation and respiratory effort for anaesthetised patients who developed cardiac arrest ${ }^{[1,2]}$. It subsequently began to be applied to all hospital inpatients, and concern was expressed that it might inappropriately prolong the death of patients who were in the terminal stage ${ }^{[3]}$.In an effort to prevent this, DNAR orders were developed in the 1970s in the United States ${ }^{[4]}$. 
Many countries now use DNAR orders but not all have a specific legal framework. Physicians have expressed dissatisfaction at their own understanding of the issues involved ${ }^{[5]}$. There is also considerable variation in the formulation, recording and practice of DNAR orders ${ }^{[6-8]}$. Nurses also encounter DNAR orders frequently and there are few published studies which have examined their perspective ${ }^{[9]}$. Not enough is known about nurses' interaction with DNAR orders and how involved nurses are, or wish to be, in the decision-making process.

\section{Aim}

We aimed to explore the opinions and experiences of nursing staff on DNAR orders, using a structured tool.

\section{Methods}

Cross-sectional survey of all nurses working on inpatient wards over a 24 hour period, on 2 sites: a university teaching hospital with 851 beds including medical, surgical, psychiatry and day-case; and a rehabilitation hospital with 52 beds and a co-located 91-bed continuing care ward.

Table 1. Survey questionnaire \& summary of responses

\begin{tabular}{|c|c|c|}
\hline No & Question text & Responses \\
\hline 1 & Please indicate your nursing experience in years & (See Table 2) \\
\hline 2 & Are you aware of a written hospital policy on DNAR orders? & $\begin{array}{l}\text { Yes } 33 \% \\
\text { No } 67 \%\end{array}$ \\
\hline 3 & If resuscitation status has NOT been decided for a patient what do you do? & $\begin{array}{l}\text { Do Resuscitate } 91 \% \\
\text { Do Not Resuscitate } 9 \%\end{array}$ \\
\hline 4 & $\begin{array}{l}\text { How do you know which patients are DNAR? (more than one response } \\
\text { possible) }\end{array}$ & $\begin{array}{l}\text { Written in medical notes } 99 \% \\
\text { Written in nursing notes } 62 \% \\
\text { Written on patient board } 4 \% \\
\text { Verbal handover from nurses } 56 \% \\
\text { Don't know } 0 \% \\
\text { Other: } 0 \%\end{array}$ \\
\hline 5 & Who should decide on DNAR status? (more than one response possible) & $\begin{array}{l}\text { Consultant } 91 \% \\
\text { Registrar } 43 \% \\
\text { Senior House Officer } 11 \% \\
\text { Intern } 3 \% \\
\text { (Rank of hospital physician, in } \\
\text { decreasing order) } \\
\text { Nurse } 22 \% \\
\text { Patient } 64 \% \\
\text { Family } 74 \%\end{array}$ \\
\hline 6 & Should the patient be informed? & $\begin{array}{l}\text { Always } 45 \% \\
\text { Sometimes } 47 \% \\
\text { Never } 8 \%\end{array}$ \\
\hline 7 & $\begin{array}{l}\text { If yes, who should inform the patient? } \\
\text { (more than one response possible) }\end{array}$ & $\begin{array}{l}\text { Physician } 87 \% \\
\text { Nurse } 25 \% \\
\text { Family } 35 \% \\
\text { Nobody } 0 \%\end{array}$ \\
\hline 8 & What format are most DNAR orders: & $\begin{array}{l}\text { Written 52\% } \\
\text { Verbal 3\% } \\
\text { Both written and verbal 45\% } \\
\text { Neither 0\% }\end{array}$ \\
\hline
\end{tabular}

Table 1 continued on page 45 
Table 1. (Continued.)

\begin{tabular}{ll}
\hline No & Question text \\
\hline 9 & Do you think that DNAR orders are clear? \\
$10 \quad$ Do physicians discuss DNAR orders with you? \\
$11 \quad$ Do physicians make the right DNAR decisions? \\
$12 \quad$ Should all hospital patients be routinely asked if they would like to be DNAR?
\end{tabular}

\section{Responses}

Always 24\%

Sometimes $70 \%$

Never 6\%

Always 22\%

Sometimes 63\%

Never 15\%

Always 24\%

Sometimes 74\%

Never 2\%

Yes $52 \%$

No $48 \%$

Always 33\%

Sometimes 55\%

Never $12 \%$

Always 7\%

Sometimes $81 \%$

Never $12 \%$

Always 10\%

Sometimes $74 \%$

Never 16\%

Always 4\%

Sometimes 63\%

Never 33\%

Oxygen 87\%

IV fluids $64 \%$

Which of the following treatments IS appropriate in a patient who is NOT for 17 resuscitation:

(more than one response possible)

18 Do you think DNAR orders are effectively used?

19 What \% of cardiac arrests that you have attended have been successful?

20 Have you ever disagreed with a DNAR decision?

21 What would you do if you did not agree with a DNAR decision?

22 Are you happy with your resuscitation skills?

23 Do you think you need more training?

24 Is there anything you would do to improve DNAR protocols?
Antibiotics 39\%

NG feeding 36\%

Intubation 3\%

Defibrillation 2\%

NONE of these $0 \%$

Always 26\%

Sometimes $67 \%$

Never 7\%

Mean response 34\%

Yes 35\%

No 65\%

Comply 36\%

Refuse to comply $0 \%$

Other: 64\% (See Table 3)

Yes $54 \%$

No $46 \%$

Yes $76 \%$

No $24 \%$

(See Table 4) 
A 24-item questionnaire was developed by the authors after consulting with experts and conducting a literature review. The questionnaire was piloted with 3 nurses involved with outpatient care. The tool was redrafted using feedback drawn from this process to improve the clarity of the questions and to allow some open text answers to explore opinions in a less rigid manner. The final questionnaire comprised both quantitative and qualitative elements (see Table 1). Opinions were sought on local DNAR policy, how DNAR orders should be made and used, and what treatments were appropriate in a patient with a DNAR order. Nurses were also asked about their experience of cardiac arrests and their satisfaction with their skills and training. Chairman's approval was given by the Chair of the local ethics committee.

\section{Results}

Two hundred and fifty one nurses were invited to participate in the study. One hundred and seventy-eight completed forms were received for a response rate $70.9 \%$. Table 1 demonstrates the questionnaire and summarises the main results.

Table 2 shows the distribution of staff responders in the three clinical areas. They comprised general surgical and medical wards (including an acute geriatric medicine ward), intensive care areas, coronary care unit, the emergency department and all other inpatient wards.

Nurses had an overall mean of 13 years of experience (range 1-40) and had worked in a median of 3 hospitals (range 1-18).

Table 2. Distribution of staff responders

\begin{tabular}{lll}
\hline Area & Number of responses & Mean staff experience in years \\
\hline Acute Hospital Wards & 140 & 12 (range 1-39) \\
Rehabilitation hospital & 24 & 15 (range 3-42) \\
Continuing care wards & 14 & 12 (range 4-30) \\
\hline
\end{tabular}

\subsection{Free responses}

Respondents were given the opportunity to provide general opinions or feedback in two areas of the survey. In Question 21, they were asked to comment on what they might do if they disagreed with a DNAR decision. These comments are shown in Table 3.

Table 3. Answers to "What would you do if you did not agree with a DNAR decision?"

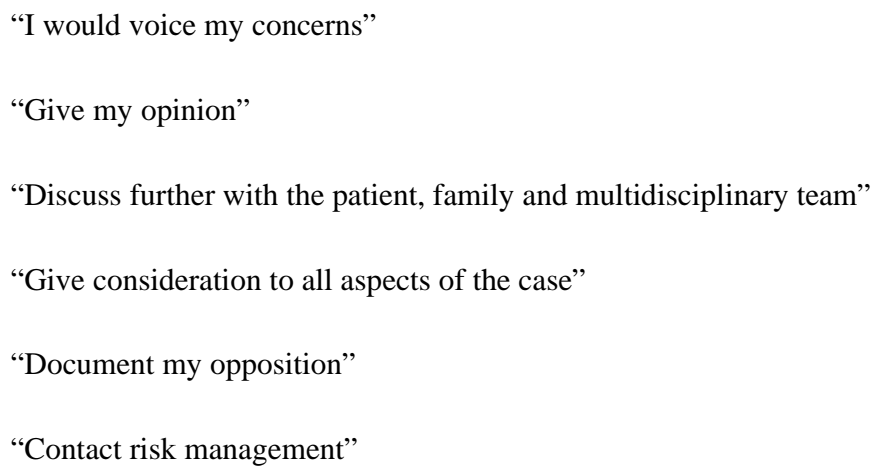

In Question 24 they were asked “What would you do to improve DNAR policy?” Some of the responses are listed in Table 4. 
Table 4. Answers to "What would you do to improve DNAR policy?"

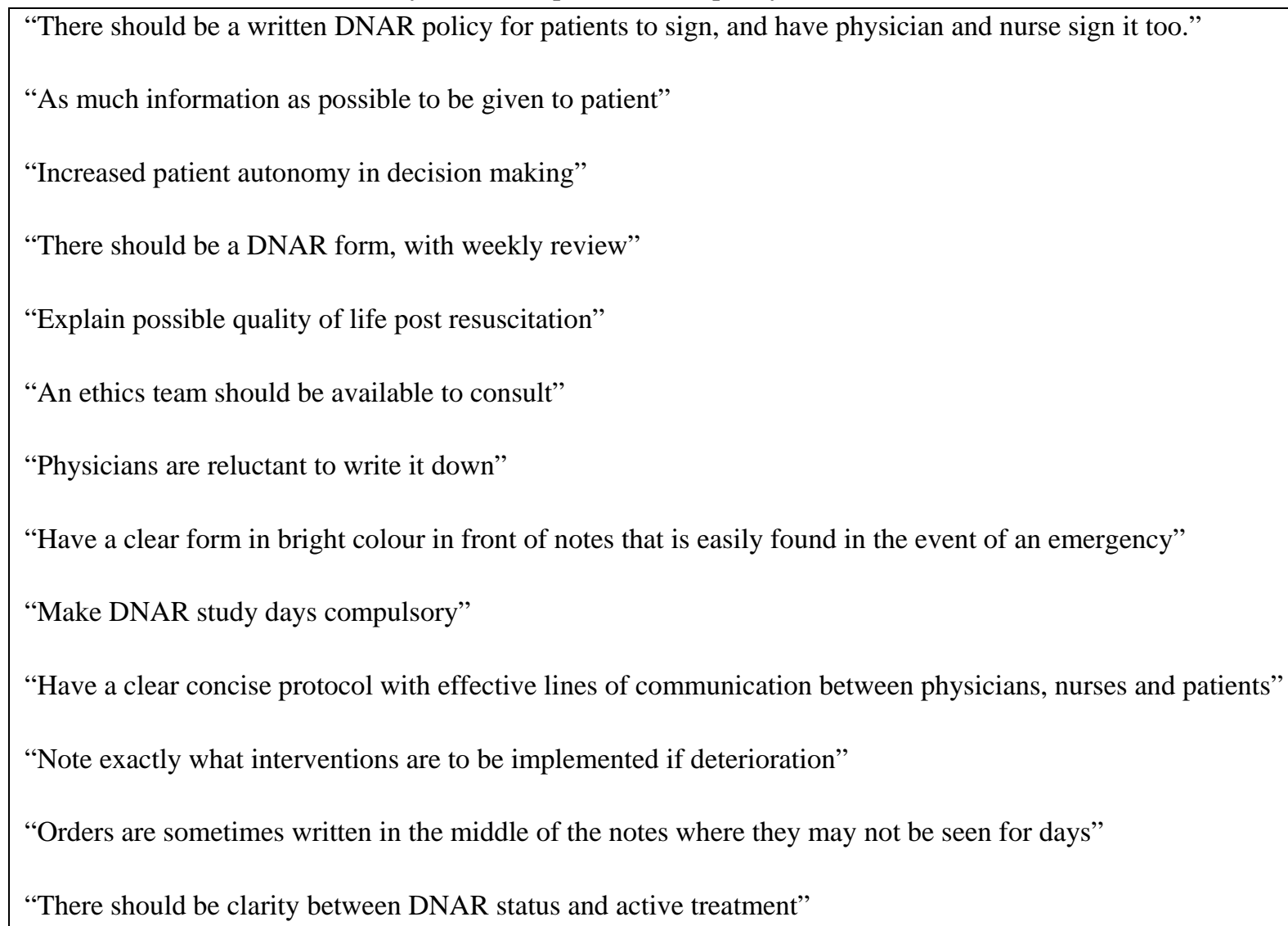

\section{Discussion}

Many clinical areas do not have an official written policy on DNAR orders ${ }^{[5]}$.This study was conducted within one institution comprising three hospital areas across two sites with a diverse patient population. At the time the study was conducted, there was no DNAR policy. However, one third of respondents reported being aware of one, suggesting that informal policies are in existence. In this study, most DNAR orders were in written form only (52\%), with a further $45 \%$ both written and verbal. However, nurses reported using medical notes (99\%), nursing notes (62\%) and verbal handover from nurses (56\%) to remain informed as to resuscitation status (more than one response was possible). Just $4 \%$ reported that it was marked on the patient list board in the ward.

When asked whether DNAR orders worked well, only 24\% felt that they were always clear, and 26\% responded that they were always used effectively. Two thirds of respondents reported that physicians only explained their decisions sometimes, and $11 \%$ said that they never did. However just $2 \%$ felt that physicians never make the right decisions about DNAR orders, with $74 \%$ saying sometimes and $24 \%$ always.

Over a third reported that they had disagreed with a DNAR decision on some occasion, and when asked if they would comply with the order in any case, one third also said they would. An open text box allowed further exploration of this area.

There were some findings that deserve further exploration—when asked what the default position was if no DNAR order had been made, $9 \%$ reported that they would not resuscitate. Of these, over half were on rehabilitation or continuing care 
wards. Their response may have been due to a lack of resuscitation facilities in these care areas. However, more education may be required to reinforce optimal clinical pathways.

In addition, many respondents considered Oxygen, IV fluids, Antibiotics and Nasogastric feeding inappropriate in patients who had DNAR orders. Generally DNAR orders do not preclude such treatment. It appears that there is still some confusion over patients in whom a decision has been made not to offer further treatment because of palliation, and those who simply have a DNAR order (where all treatment options may be considered). There is of course overlap between the two areas and patients should be given an individual care plan that deals effectively with their needs. A small number of respondents also reported that intubation and defibrillation would be appropriate even in the presence of a DNAR order.

The profile of the respondents showed that there is a wealth of nursing experience on the wards, with a mean of 13 years' experience per respondent. They had worked in a median of 3 hospitals during their careers. In general they overestimated the percentage of cardiac arrests that had a successful outcome (34\%). The accepted figure is probably about $17-23 \%$, though there is variation in different ward areas ${ }^{[10,11]}$.

In the UK there is no national policy on DNAR orders, but many professional bodies have issued their own guidance. Recent guidelines issued by the British Medical Association, the Royal College of Nursing and the Resuscitation Council state that nurses are encouraged to take more involvement in DNAR decisions ${ }^{[12]}$. In some situations senior nurses can make these decisions. When asked who should decide, $91 \%$ of the respondents in this study felt it should be the consultant (the most senior member of the medical team). Only 22\% felt that the nurse should have a role. This contrasts with a study by Thibault-Prevost et al, where $81 \%$ of respondents felt that nurses should be involved (although these were nurses working in the intensive care unit) ${ }^{[13]}$. However there was a clear feeling that the most junior physicians should not be making these decisions. More than two thirds felt that the patient or their family should have a role. This is similar to the study by Giles and Moule where $81 \%$ of respondents felt that the family should be involved ${ }^{[14]}$.

Almost half of nurses surveyed would like to see all patients being asked routinely on admission whether they would like to be resuscitated. Forty-five percent agreed that patients should always be informed of a DNAR order concerning them, but $47 \%$ said "sometimes". The clinical situation does indeed demand on some occasions that patients should not be informed, e.g., if it were a futile intervention or if the knowledge might cause them some harm ${ }^{[15]}$. However it is accepted that one should maximise patient involvement in DNAR decisions ${ }^{[16]}$. The vast majority of respondents felt that it was the physician's responsibility to keep the patient informed. Only 25\% felt that nurses had a responsibility to keep them informed, which again suggests a less involved position compared to the status quo in the UK.

Just over half of nurses surveyed were happy with their resuscitation skills, but three quarters said they would like more training. Currently, most clinical areas require their staff to renew their resuscitation certification every two years. Training is organised by the British Heart Foundation and provided at local centres. This suggests some dissatisfaction with training received in this process.

Previous studies in this area have focussed on one particular nursing specialty, such as critical care, oncology or geriatric medicine $^{[13,17,18]}$. This survey was performed in a university teaching hospital, and included nursing staff from many varied ward areas. The response rate was particularly good at almost $71 \%$, representing an interest in this topic among the respondents. The rate may have been increased by performing the questionnaire over multiple days. The questionnaire used allowed for a diverse range of views to be expressed and several aspects of DNAR orders were explored.

It is clear that further work on guidelines for DNAR orders is required. Opinions should be sought from all stakeholders. Some clear and practical suggestions were made in the free text responses in this survey. Nurses are an important and often neglected group when it comes to resuscitation decisions. Reform of DNAR guidelines should consider their views. In addition it is clear that interprofessional education should be employed to help achieve better cooperation between healthcare staff in this important and relevant area. 
Study limitations: This was a single-centre questionnaire, performed over a short period of time. Results may not be generalisable to other contexts.

\section{Conclusion}

There is considerable interest in DNAR orders among nursing staff. Most expressed dissatisfaction with regard to how DNAR orders work, and in particular, with a perceived lack of communication from physicians. There is a need for more education in this area, and DNAR guidelines should be formulated considering the views of all stakeholders. Nurses involved in our study may not have the same desire to become more involved in making DNAR orders as their UK counterparts.

\section{Key points:}

- Nurses feel that DNAR orders are not sufficiently clear

- Communication of DNAR status, especially from physicians, could be improved

- The vast majority of nurses felt that senior physicians should make DNAR decisions, not nurses

- Almost half of the respondents felt that everyone admitted to hospital should have their DNAR status documented

- Most nurses would like more training to improve their resuscitation skills

\section{Conflict of interest statement}

The authors declare that they have no conflict of interest.

\section{Role of the funding source}

There was no funding received.

\section{References}

[1] Kouwenhoven WB, Jude JR, Knickerbocker GG. Closed-chest cardiac massage, JAMA. 1960; 173:94-97. http://dx.doi.org/10.1001/jama.1960.03020280004002

[2] Committee on CPR of the Division of Medical Sciences, National Academy of Sciences-National Research Council, Cardiopulmonary resuscitation, JAMA. 1966; 198:372-379 and 138-145.

[3] Symmers WS. Not allowed to die. BMJ. 1968; 1: 442. PMid:5639634 http://dx.doi.org/10.1136/bmj.1.5589.442

[4] Standards for cardiopulmonary resuscitation (CPR) and emergency cardiac care (ECC). V. Medicolegal considerations and recommendations. JAMA. 1974; 227(Suppl):864-866. PMid:4405914

[5] Butler MW, Saaidin N, Sheikh AA, Fennell JS. Dissatisfaction with Do Not Attempt Resuscitation Orders: A nationwide study of Irish consultant physician practices. Ir Med J. 2006 Jul-Aug; 99(7):208-10. PMid:16986566

[6] McNamee J, O'Keeffe ST. Documentation of do-not-resuscitate orders in an Irish hospital. Ir J Med Sci. 2004 Apr-Jun; 173(2):99-101. PMid:15540713 http://dx.doi.org/10.1007/BF02914567

[7] Goodlin SJ, Zhong Z, Lynn J, Teno JM, Fago JP, Desbiens N, Connors AF Jr, Wenger NS, Phillips RS. Factors associated with use of cardiopulmonary resuscitation in seriously ill hospitalized adults. JAMA. 1999 Dec 22-29; 282(24):2333-9.PMid:10612321 http://dx.doi.org/10.1001/jama.282.24.2333

[8] Shepardson LB, Youngner SJ, Speroff T, O'Brien RG, Smyth KA, Rosenthal GE. Variation in the use of do-not-resuscitate orders in patients with stroke. Arch Intern Med. 1997 Sep 8; 157(16):1841-7. PMid:9290543 http://dx.doi.org/10.1001/archinte.1997.00440370081008

[9] Palmer R. A review of nurses' attitudes towards DNAR decisions. Nursing Times. 2007; 97: 37, 32-37.

[10] Dumot JA, Burval DJ, Sprung J, Waters JH, Mraovic B, Karafa MT, Mascha EJ, Bourke DL. Outcome of adult cardiopulmonary resuscitations at a tertiary referral center including results of "limited" resuscitations. Arch Intern Med. 2001 Jul 23; 161(14):1751-8. PMid:11485508 http://dx.doi.org/10.1001/archinte.161.14.1751 
[11] Peberdy MA, Kaye W, Ornato JP, Larkin GL, Nadkarni V, Mancini ME, Berg RA, Nichol G, Lane-Trultt T. Cardiopulmonary resuscitation of adults in the hospital: a report of 14720 cardiac arrests from the National Registry of Cardiopulmonary Resuscitation. Resuscitation. 2003 Sep; 58(3):297-308. http://dx.doi.org/10.1016/S0300-9572(03)00215-6

[12] White C. Cardiopulmonary resuscitation decisions should be extended to nurses. BMJ. 2007; 335:901. PMid:17974659 http://dx.doi.org/10.1136/bmj.39384.681829.DB

[13] Thibault-Prevost J et al. Critical care nurses' perceptions of DNR status. Journal of Nursing Scholarship. 2000; 32(3):259-265. PMid:12462820 http://dx.doi.org/10.1111/j.1547-5069.2000.00259.x

[14] Giles H, Moule P. Do not attempt resuscitation decision making: a study exploring the attitudes and experiences of nurses. Nursing in Critical Care. 2004; 9(3):115-122. http://dx.doi.org/10.1111/j.1362-1017.2004.00065.x

[15] O'Keeffe S. Development and implementation of resuscitation guidelines: a personal experience. Age Ageing. 2001 Jan; $30: 19-25$. PMid:11322667 http://dx.doi.org/10.1093/ageing/30.1.19

[16] Covinsky KE, Fuller JD, Yaffe K, Johnston CB, Hamel MB, Lynn J, Teno JM, Phillips RS. Communication and decision-making in seriously ill patients: findings of the SUPPORT project. The Study to Understand Prognoses and Preferences for Outcomes and Risks of Treatments. J Am Geriatr Soc. 2000 May; 48(5 Suppl): S187-93. PMid:10809474

[17] Bass M. Oncology nurses' perceptions of their role in resuscitation decisions. Professional Nurse. 2003; 18(12):710-715. PMid:12955945

[18] De Gendt C et al. Nurses' involvement in 'do not resuscitate' decisions on acute elder care wards. Journal of Advanced Nursing. 2007; 57(4): 404-409. PMid:17291204 http://dx.doi.org/10.1111/j.1365-2648.2007.04090.x 